\title{
WORK-RELATED COGNITIVE RESERVE PREDICTS COGNITIVE FUNCTIONING AND DEPRESSION IN OLDER ADULTS
}

\author{
Kristīne Šneidere \\ Rīga Stradiņš University, Latvia \\ Zane Ozolina \\ Rīga Stradiņš University, Latvia \\ Ainārs Stepens \\ Rīga Stradiņš University, Latvia
}

\begin{abstract}
In the past decade, there has been a rapid increase in people aged over 65 - in Latvia, it constitutes 34\% of the population. It has been well established that depression is one of the psychiatric diseases often comorbid to dementia, therefore it is important to identify life-style related factors that could contribute not only to the delay of dementia symptoms but also decrease the possibility of depression in older adults. Thus the study aimed to investigate the relationship between work-related cognitive reserve, depression and overall cognitive functioning in older adults with no diagnosis of dementia or depression.

84 older adults aged from $65-92$ (Mdn $=77, S D=6.17,76 \%$ women) with no diagnosis of dementia or depression participated in the study. To assess work-related cognitive reserve, Cognitive Reserve Index questionnaire (Nucci, Mapelli, \& Mondini, 2012) was used, while for depression measures the 15- item Geriatric Depression Scale (Sheikh \& Yesavage, 1986) was used. Overall cognitive functioning was measured using The Montreal Cognitive Assessment scale (Nasreddine et al., 2015).

To identify the relationship between the three variables, Spearman correlation coefficient was used. All variables correlated significantly. Both, work-related cognitive reserve and depression, predicted cognitive functioning $\left(\Delta R^{2}=.17, F(1,82)=17.13, p=.000\right.$ and $\left.\Delta R^{2}=.147, F(1,82)=14.17, p=.000\right)$ accordingly. These results offer an insight into the possible positive contribution of the cognitive reserve not only to cognitive functioning, but also psychological well-being later in life. More studies in larger samples should be conducted to confirm the observation from this study.
\end{abstract}

Keywords: cognitive reserve, work-related cognitive reserve, depression, cognitive functioning, older adults.

\section{Introduction}

The increased economic burden of such mental diseases as dementia and depression has become a major health economic challenge in Europe, costing more than 200 billion euros per year (Olesen et al., 2012). In Latvia, patients with 
dementia constitute for $6 \%$ of the registered mental patients, with mood disorders constituting for $8 \%$. An unhealthy diet, lack of physical activities and addictive health habits have been identified as the main lifestyle-related health risk factors for dementia in Latvia, according to the Ministry of Health of the Republic of Latvia. Depression is considered to be both - a risk factor and prodrome in the case of dementia and mild cognitive impairment (Enache, Winblad, \& Aarsland, 2011) and estimated 30.3\% dementia patients also suffer from major depressive disorder. Depression in these patients significantly affects not only them, but also their caregivers and society (Goodarzi, Mele, Roberts, \& Holroyd-Leduc, 2017).

Despite knowing the main risk factors for dementia (e.g. the increased number of APOE $\varepsilon 4$ alleles (Qiu, Kivipelto, \& von Strauss, 2009), cardiovascular diseases (Skoog \& Gustafson, 2003), diabetes mellitus (Roberts et al., 2008), smoking and heavy drinking (Collins, Sachs-Ericsson, Preacher, Sheffield, \& Markides, 2009), and unhealthy eating habits (Huang et al., 2005), the incidence of dementia is only growing and effective treatment still has to be found. Therefore, attention should be paid to illness prevention. While lifestyle habits present several risks for dementia, they may also function as protective factors. It has been found that education, social networking and mental activity (i.e. cognitive reserve) might postpone cognitive decline and neurodegeneration (Steffener \& Stern, 2012). Cognitive reserve (CR) offers an active model of adapting of cognitive processes to brain functioning in case of a sudden change in the brain or brain damage (Stern et al., 2018).

Differences in abilities to overcome a pathology or display symptoms of neurological disease have for long been attributed to different factors, starting with genetics and nowadays moving towards life-style related effects on cognition. Among the best-known studies indicating the competition between nature and nurture, is the longitudinal Nun Study (Snowdon, 2003) that showed that those, who had more linguistic ability and who showed positive emotions in early in life, as well as those who had higher education, were less likely to experience rapid cognitive decline or dementia symptoms later in life despite there being actual changes in post-mortem brain measures. This is among one of the studies that stimulated the development of the cognitive reserve concept as the study indicated one significant aspect - despite the visible pathology, the individual can still express no cognitive, emotional or behavioural symptoms of dementia. Yaakov Stern (2002) got to a similar conclusion after noticing significant differences in recovery from brain lesions in similar regions in patients with different education levels, with higher educated patients having a shorter rehabilitation period. Nowadays, the concept of cognitive reserve and the role of education is well established; however, such life-style factors as working activity and leisure activity are still being overlooked, therefore, the aim of this study was 
to investigate the relationship between work-related cognitive reserve, depression symptoms and cognitive functioning.

\section{Methodology}

\section{Participants}

84 older adults aged from $65-92(\mathrm{Mdn}=77, \mathrm{SD}=6.17,76 \%$ women $)$ with no diagnosis of dementia or depression participated in the study. Inclusion/exclusion criteria for the participants were as follows: native Latvian speakers, at least 65 years old and no diagnosis of neurodegenerative or psychiatric diseases.

\section{Materials}

Overall cognitive functioning was assessed using the Montreal Cognitive Assessment scale (MoCA, Nasreddine et al., 2005). This test includes 11 tasks evaluating executive functions, visuospatial perception, memory, verbal fluency, attention, generalisation and orienting in space and time. MoCA task is devised to identify even mild cognitive impairment.

To investigate working activity, Cognitive Reserve Index questionnaire (CRIq, Nucci, Mapelli, \& Mondini, 2012) was used. This questionnaire is used for standardized estimation of cognitive reserve and its three underlying factors or subscales: education (comprised of formal and vocational studies), working activity (measured in five levels according to the amount of responsibility and education needed to work) and leisure time (including weekly, monthly and annual activities since the age of 18).

Depression was assessed using Geriatric Depression Scale 15-item questionnaire (GDS-15, Yesavage \& Sheikh, 1986) that aims to identify symptoms of depression in older adults. Higher scores indicate a higher possibility of depression in the participant. The questionnaire includes 15 closed questions with yes/no answers.

\section{Procedure}

Participants were recruited through different senior organisations as well as mass media. All data were obtained frontally and individually, all participants had good or corrected vision and hearing. Prior to the assessment, participants were inquired regarding their age, native language and medical history and only those participants that complied with the inclusion/exclusion criteria were invited to participate in the study. 


\section{Research results}

All data were analysed with IBM SPSS 21. To determine whether the data comply with normal distribution, Kolmogorov-Smirnov Z test was executed; however, only Work-related CR measures indicated compliance with normal distribution, therefore, non-parametric statistics methods were used later in the data analysis. In Table 1, descriptive statistics of all tests and their subscales are given.

Table 1 Descriptive statistics of MoCA task, Geriatric Depression Scale and Work-related CR

\begin{tabular}{|r|l|l|l|l|}
\hline \multicolumn{1}{|c|}{ Variable } & \multicolumn{1}{c|}{ Mdn } & \multicolumn{1}{c|}{ SD } & \multicolumn{1}{c|}{ Min-Max } & \multicolumn{1}{c|}{ Z score } \\
\hline MoCA & 25 & 3.55 & $14-29$ & $1.54^{*}$ \\
\hline Visuospatial scale & 3 & 1 & $0-4$ & $2.17^{*}$ \\
\hline Naming scale & 3 & .34 & $0-5$ & $4.76^{*}$ \\
\hline Memory scale & 3 & 1.58 & $0-5$ & $1.61^{*}$ \\
\hline Attention scale & 5 & .97 & $2-6$ & $2.58^{*}$ \\
\hline Verbal scale & 3 & .77 & $0-3$ & $2.79^{*}$ \\
\hline Generalisation scale & 2 & .77 & $0-2$ & $2.99^{*}$ \\
\hline Orientation scale & 6 & .95 & $1-6$ & $4.38^{*}$ \\
\hline Work-related CR & 113 & 24.9 & $73-206$ & .99 \\
\hline GDS & 2 & 2.46 & $0-11$ & $2.52^{*}$ \\
\hline
\end{tabular}

Note. MoCA - Montreal Cognitive Assessment, CR - cognitive reserve, GDS - Geriatric Depression Scale, * $-p<.05$.

To evaluate the relationship between cognitive functioning, depression and work-related CR, Spearman's rank correlation coefficient was used. MoCA test statistically significantly correlated with both - depression $\left(\mathrm{r}_{\mathrm{s}}=-.28, \mathrm{p}>.01\right)$ and work-related CR $\left(\mathrm{r}_{\mathrm{s}}=.41, \mathrm{p}<.01\right)$. Exploring MoCA task scales in regards to work-related CR and depression, correlations between work-related CR and Visuo-spatial perception $\left(\mathrm{r}_{\mathrm{s}}=.39, \mathrm{p}<.01\right)$ and Language subscales $\left(\mathrm{r}_{\mathrm{s}}=.38\right.$, $\mathrm{p}<.01$ ) were found. Depression significantly, however, weakly, correlated only with Language subscale $\left(\mathrm{r}_{\mathrm{s}}=-.28, \mathrm{p}<.01\right)$. All MoCA task scales, apart from Naming scale, significantly correlated with the total MoCA score $\left(r_{s}=.24-.66\right.$, $\mathrm{p}<.05$ ), which shows that the items are reasonably homogenous (for more detail please see Table 2). 
SOCIETY. INTEGRATION. EDUCATION

Proceedings of the International Scientific Conference. Volume VII, May $22^{\text {th }}-23^{\text {th }}$, 2020. 168-176

Table 2 Spearman's rank correlation between MoCA task and subscales, Geriatric Depression Scale and work-related $C R$

\begin{tabular}{|l|c|c|c|c|c|c|c|c|c|c|c|}
\hline \multicolumn{1}{|c|}{ Variable } & 1. & 2. & 3. & 4. & 5. & 6. & 7. & 8. & 9. & 10. & 11. \\
\hline 1.MoCA & -- & & & & & & & & & & \\
\hline $\begin{array}{l}2 . \quad \text { Executive } \\
\text { fns }\end{array}$ & $.55^{* *}$ & -- & & & & & & & & & \\
\hline 3.Visuospatial & $.66^{* *}$ & $.50^{* *}$ & -- & & & & & & & & \\
\hline 4.Naming & .15 & .05 & .12 & -- & & & & & & & \\
\hline 5.Memory & $.62^{* *}$ & $.22^{*}$ & .20 & -.05 & -- & & & & & & \\
\hline 6.Attention & $.56^{* *}$ & $.26^{*}$ & $.29^{* *}$ & -.07 & .11 & -- & & & & & \\
\hline 7.Language & $.62^{* *}$ & $.39^{* *}$ & $.53^{* *}$ & .13 & .07 & $.36^{* *}$ & -- & & & & \\
\hline $\begin{array}{l}\text { 8.Generalizati } \\
\text { on }\end{array}$ & $.37^{* *}$ & .11 & .06 & -.01 & -.00 & $.25^{*}$ & $.31^{* *}$ & -- & & & \\
\hline 9.Orientation & $.24^{*}$ & .14 & .11 & -.06 & .16 & .01 & .07 & -.05 & -- & & \\
\hline 10.GDS & $-.28^{* *}$ & -.11 & -.10 & .14 & -.21 & -.22 & $-.28^{* *}$ & -.20 & -.17 & -- & \\
\hline 11.Work CR & $.41^{* *}$ & .18 & $.39^{* *}$ & .10 & .21 & .25 & $.38^{* *}$ & .18 & .16 & $-.34^{* *}$ & -- \\
\hline
\end{tabular}

Note. MoCA - Montreal Cognitive Assessment, fns - functions, CR - cognitive reserve, GDS Geriatric Depression Scale, $*-p<.05, * *<.01$.

As significant relationships between MoCA test, work-related CR and depression were found, a linear regression analysis was conducted to investigate weather CR and depression can predict overall cognition (see Table 3).

Table 3 Linear regression analysis results

\begin{tabular}{|l|l|l|l|l|l|l|l|}
\hline & $R$ & $\Delta R^{2}$ & $F$ & $B$ & $\beta$ & $t$ & $p$ \\
\hline $\begin{array}{l}\text { Geriatric } \\
\text { Depression } \\
\text { Scale }\end{array}$ & .38 & .15 & 14,17 & -.56 & -.38 & -3.76 & .00 \\
\hline Working CR & .42 & .17 & 17.13 & .06 & .42 & 4.14 & .00 \\
\hline
\end{tabular}

Note. $C R$ - cognitive reserve

Both, work-related cognitive reserve and depression, predicted cognitive functioning $\left(\Delta R^{2}=.17, F(1,82)=17.13, p=.000\right.$ and $\Delta R^{2}=.15, F(1,82)=14.17$, $p=.000)$ accordingly (See Table 3).

Multiple regression was run to predict cognitive functioning from depression and work-related cognitive reserve. These variables statistically significantly predicted cognitive functioning $\left(\Delta R^{2}=.23, F(2,81)=11.97, p=.01\right)$. Both variables added statistically significantly to the prediction $(p<.05)$ (see Figure 1 ). 


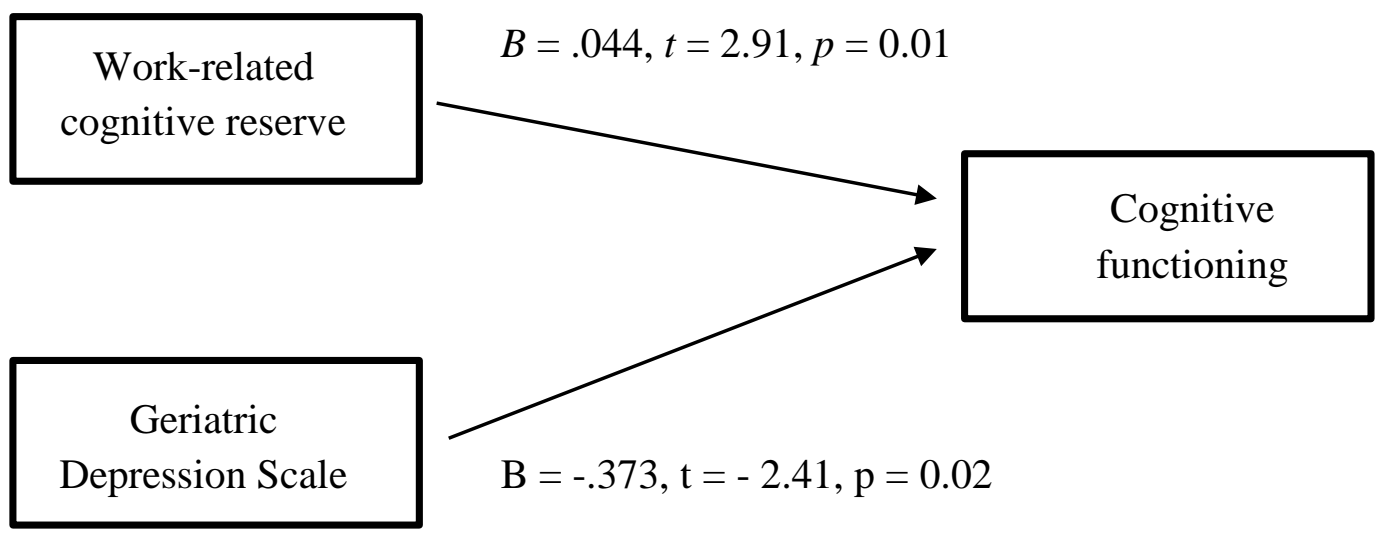

Figure 1 Multiple regression analysis results

\section{Discussion}

This paper aimed to illustrate the relationship between work-related cognitive reserve, depression and cognitive functioning, and the main results indicate not only that there are statistically significant though weak correlations between these three variables. Depression and work-related CR also predicted $23 \%$ of the overall cognitive functioning score.

Lately, a vast amount of studies have indicated a relationship between depression and cognitive functioning and, while it is still unclear, whether depression is a result of cognitive impairment or vice versa, acute and persisting depression have been linked to a cognitive impairment also known as pseudodementia (Perini et al., 2019). Even though in our study the relationship between general cognitive functioning and depression was weak, it should be taken into consideration that only older adults without previous diagnosis of depression or cognitive impairment were included in the study, thus the low correlation can be easily explained with the low levels of depression and lack of diagnosed cognitive impairment (Gale, Allerhand, \& Deary, 2012).

Similarly, significant though weak relationship between work-related CR and depression was found, indicating that bigger responsibility, social and intellectual involvement at work might be related to lower levels of depression symptoms. However, here as well it should be taken into consideration that the mean levels of depression symptoms were rather low. At the same time, social aspects of depression should be taken into account - such factors as working in rotating shifts (Kalmbach, Pillai, Cheng, Arnedt, \& Drake, 2015), high psychological job demands and job insecurity has been found to predict the onset of depression (Andrea, Bültmann, Van Amelsvoort, \& Kant, 2009). This in a way contradicts the results, as high demanding job is one of the criteria for higher work-related CR, thus another possible explanation for the negative relationship 
could be found in the fact that having job often gives the chance for having a larger social network, which in turn has been a positive factor for lower levels of depression (Visentini, Cassidy, Bird, \& Priebe, 2018).

Considering the relationship found between work-related CR and cognitive functioning, there have been rather contradictory results. While most of the studies indicate the role of CR in cognitive functioning in adults with dementia (Mondini et al., 2016) or after mild traumatic brain injury (Stenberg et al., 2019), most studies do not find this relationship in healthy adults. One of the possible explanations for this is that CR in cognitively healthy adults function as extra help in cases when the individual is confronted with challenging tasks and there is no need for the extra involvement in normal cognitive assessment tasks.

Overall, the study indicates that it would be worthwhile to include the assessment of CR in neuropsychological evaluations, as it could offer an insight into predictable rehabilitation time and outcomes. This study also contributes to previous studies showing that neuropsychological assessment can give faulty results in case of high cognitive reserve, as the onset of dementia symptoms has been delayed.

This study met several limitations. Firstly, only participants who reported no diagnosis of neurodegenerative diseases or depression were included in the study. While it would be beneficial to include clinical group in such study, it should be taken into consideration that Cognitive Reserve Index questionnaire is memorybased; therefore - not an objective measure. Knowing that memory is among cognitive processes that suffer the most from the aforementioned diseases, the data obtained may not be reliable., which is finding a possible biomarker for CR. Secondly, while MoCA task is widely used all over the world, it still has not been standardised for Latvian sample and more vigorous study including clinical sample should be conducted. Results of this study showed that the Naming scale did not have significant relationship with the total MoCA score, thus it could be worthwhile to investigate the actual use of this scale in a larger scale.

Overall the study indicates possible relationship between work-related CR, depression and overall cognitive functioning, with the first two variables possibly even predicting the cognitive functions; however, more rigorous study using clinical group and excluding the aforementioned limitations should be conducted.

\section{References}

Andrea, H., Bültmann, U., Van Amelsvoort, L.G.P.M., \& Kant, Y. (2009). The incidence of anxiety and depression among employees - The role of psychosocial work characteristics. Depression and Anxiety, 26(11), 1040-1048. DOI: https://doi.org/10.1002/da.20516

Collins, N., Sachs-Ericsson, N., Preacher, K.J., Sheffield, K.M., \& Markides, K. (2009). Smoking increases risk for cognitive decline among community-dwelling older Mexican Americans. The American Journal of Geriatric Psychiatry: Official Journal of the 
Šneidere et al., 2020. Work-Related Cognitive Reserve Predicts Cognitive Functioning and

Depression in Older Adults

American Association for Geriatric Psychiatry, 17(11), 934-942. DOI: https://doi.org/10.1097/JGP.0b013e3181b0f8df

Enache, D., Winblad, B., \& Aarsland, D. (2011). Depression in dementia: epidemiology, mechanisms, and treatment. Current Opinion in Psychiatry, 24(6), 461-472. DOI: https://doi.org/10.1097/YCO.0b013e32834bb9d4

Gale, C.R., Allerhand, M., \& Deary, I.J. (2012). Is there a bidirectional relationship between depressive symptoms and cognitive ability in older people? A prospective study using the English Longitudinal Study of Ageing. Psychological Medicine, 42(10), 2057-2069. DOI: https://doi.org/10.1017/S0033291712000402

Goodarzi, Z.S., Mele, B.S., Roberts, D.J., \& Holroyd-Leduc, J. (2017). Depression Case Finding in Individuals with Dementia: A Systematic Review and Meta-Analysis. Journal of the American Geriatrics Society, 65(5), 937-948. DOI: https://doi.org/10.1111/ jgs. 14713

Huang, T.L., Zandi, P.P., Tucker, K.L., Fitzpatrick, A.L., Kuller, L.H., Fried, L.P., ... Carlson, M.C. (2005). Benefits of fatty fish on dementia risk are stronger for those without APOE epsilon4. Neurology, 65(9), 1409-1414. DOI: https://doi.org/10.1212/01.wnl. 0000183148.34197.2e

Kalmbach, D.A., Pillai, V., Cheng, P., Arnedt, J.T., \& Drake, C.L. (2015). Shift work disorder, depression, and anxiety in the transition to rotating shifts: The role of sleep reactivity. Sleep Medicine, 16(12), 1532-1538. DOI: https://doi.org/10.1016/j.sleep.2015.09.007

Mondini, S., Madella, I., Zangrossi, A., Bigolin, A., Tomasi, C., Michieletto, M., ... Mapelli, D. (2016). Cognitive reserve in dementia: Implications for cognitive training. Frontiers in Aging Neuroscience, 8(APR), 1-7. DOI: https://doi.org/10.3389/fnagi.2016.00084

Nasreddine, Z.S., Phillips, N.A., Bedirian, V., Charbonneau, S., Whitehead, V., Collin, I., ... Chertkow, H. (2005). The Montreal Cognitive Assessment, MoCA: A Brief Screening Tool For Mild Cognitive Impairment. Journal of the American Geriatrics Society, 53(4), 695-699. DOI: https://doi.org/10.1111/j.1532-5415.2005.53221.x

Nucci, M., Mapelli, D., \& Mondini, S. (2012). Cognitive Reserve Index questionnaire (CRIq): a new instrument for measuring cognitive reserve. Aging Clinical and Experimental Research, 24(3), 218-226.

Olesen, J., Gustavsson, A., Svensson, M., Wittchen, H.-U., Jönsson, B., CDBE2010 study group, \& European Brain Council. (2012). The economic cost of brain disorders in Europe. European Journal of Neurology, 19(1), 155-162. DOI: https://doi.org/10.1111/j.14681331.2011.03590.x

Perini, G., Ramusino, M.C., Sinforiani, E., Bernini, S., Petrachi, R., \& Costa, A. (2019). Cognitive impairment in depression: Recent advances and novel treatments. Neuropsychiatric Disease and Treatment, 15, 1249-1258. DOI: https://doi.org/10.2147/ NDT.S199746

Qiu, C., Kivipelto, M., \& von Strauss, E. (2009). Epidemiology of Alzheimer's disease: occurrence, determinants, and strategies toward intervention. Dialogues in Clinical Neuroscience, 11(2), 111-128. Retrieved from http://www.ncbi.nlm.nih.gov/ pubmed/19585947

Roberts, R.O., Geda, Y.E., Knopman, D.S., Christianson, T.J.H., Pankratz, V.S., Boeve, B.F., ... Petersen, R.C. (2008). Association of Duration and Severity of Diabetes Mellitus With Mild Cognitive Impairment. Archives of Neurology, 65(8), 1066-1073. DOI: https://doi.org/10.1001/archneur.65.8.1066

Skoog, I., \& Gustafson, D. (2003). Hypertension, hypertension-clustering factors and Alzheimer's disease. Neurological Research, 25(6), 675-680. DOI: https://doi.org/ 
Proceedings of the International Scientific Conference. Volume VII, May $22^{\text {th }}-23^{\text {th }}, 2020.168-176$ $10.1179 / 016164103101201986$

Snowdon, D.A. (2003). Healthy Aging and Dementia: Findings from the Nun Study. Annals of Internal Medicine, 139(5 II), 450-454. https://doi.org/10.7326/0003-4819-139-5_part_2200309021-00014

Steffener, J., \& Stern, Y. (2012). Exploring the neural basis of cognitive reserve in aging. Biochimica et Biophysica Acta - Molecular Basis of Disease, 1822(3), 467-473. DOI: https://doi.org/10.1016/j.bbadis.2011.09.012

Stenberg, J., Håberg, A.K., Follestad, T., Olsen, A., Iverson, G.L., Terry, D.P., ... Vik, A. (2019). Cognitive Reserve Moderates Cognitive Outcome After Mild Traumatic Brain Injury. Archives of Physical Medicine and Rehabilitation. DOI: https://doi.org/10.1016/ j.apmr.2019.08.477

Stern, Y. (2002). What is cognitive reserve? Theory and research application of the reserve concept. Journal of the International Neuropsychological Society: JINS, 8(3), 448-460. Retrieved from http://www.ncbi.nlm.nih.gov/pubmed/11939702

Stern, Y., Arenaza-Urquijo, E.M., Bartrés-Faz, D., Belleville, S., Cantilon, M., Chetelat, G., ... Reserve, Resilience and Protective Factors PIA Empirical Definitions and Conceptual Frameworks Workgroup. (2018). Whitepaper: Defining and investigating cognitive reserve, brain reserve, and brain maintenance. Alzheimer's \& Dementia: The Journal of the Alzheimer's Association. DOI: https://doi.org/10.1016/j.jalz.2018.07.219

Visentini, C., Cassidy, M., Bird, V.J., \& Priebe, S. (2018, December 1). Social networks of patients with chronic depression: A systematic review. Journal of Affective Disorders, Vol. 241, 571-578. DOI: https://doi.org/10.1016/j.jad.2018.08.022

Yesavage, J.A., \& Sheikh, J.I. (1986). 9/Geriatric Depression Scale (GDS). Clinical Gerontologist, 5(1-2), 165-173. 